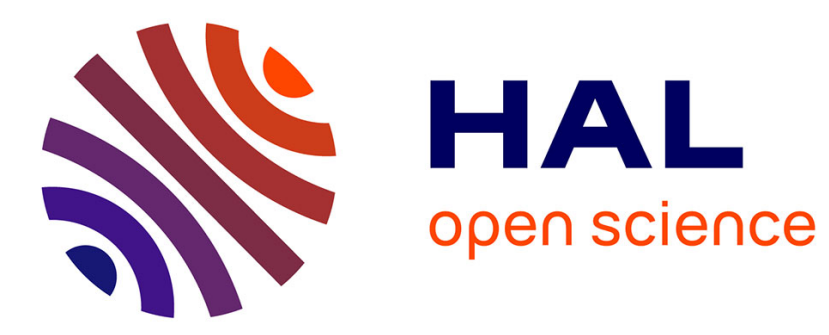

\title{
A study of verbal and nonverbal communication in Second Life - the ARCHI21 experience
}

Ciara R. Wigham, Thierry Chanier

\section{To cite this version:}

Ciara R. Wigham, Thierry Chanier. A study of verbal and nonverbal communication in Second Life - the ARCHI21 experience. ReCALL, 2013, 25, pp.XX-XX. edutice-00674138

\section{HAL Id: edutice-00674138}

\section{https://edutice.archives-ouvertes.fr/edutice-00674138}

Submitted on 25 Feb 2012

HAL is a multi-disciplinary open access archive for the deposit and dissemination of scientific research documents, whether they are published or not. The documents may come from teaching and research institutions in France or abroad, or from public or private research centers.
L'archive ouverte pluridisciplinaire $\mathbf{H A L}$, est destinée au dépôt et à la diffusion de documents scientifiques de niveau recherche, publiés ou non, émanant des établissements d'enseignement et de recherche français ou étrangers, des laboratoires publics ou privés. 


\title{
A study of verbal and nonverbal communication in Second Life - the ARCHI21 experience.
}

\author{
Ciara R. Wigham, Thierry Chanier (to appear in 2013), ReCALL 25(1)
}

\begin{abstract}
Three-dimensional synthetic worlds introduce possibilities for nonverball communication in computer-mediated language learning. This paper presents an original methodological framework for the study of multimodal communication in such worlds. It offers a classification of verbal and nonverbal communication acts in the synthetic world Second Life and outlines relationships between the different types of acts that are built into the environment. The paper highlights some of the differences between the synthetic world's communication modes and those of face-to-face communication and exemplifies the interest of these for communication within a pedagogical context.
\end{abstract}

We report on the application of the methodological framework to a course in Second Life which formed part of the European project ARCHI21. This course, for Architecture students, adopted a Content and Learning Integrated Learning approach (CLIL). The languages studied were French and English. A collaborative building activity in the students $L 2$ is considered, using a method designed to organise the data collected in screen recordings and to code and transcribe the multimodal acts. We explore whether nonverbal communication acts are autonomous in Second Life or whether interaction between synchronous verbal and nonverbal communication exists. Our study describes how the distribution of the verbal and nonverbal modes varied depending on the pre-defined role the student undertook during the activity. We also describe the use of nonverbal communication to overcome verbal miscommunication where direction and orientation were concerned. In addition, we illustrate how nonverbal acts were used to secure the context for deictic references to objects made in the verbal mode. Finally, we discuss the importance of nonverbal and verbal communication modes in the proxemic organisation of students and the iimpact of proxemic organisation on the quantity of students' verbal production and the topics discussed in this mode.

This paper seeks to contribute to some of the methodological reflections needed to better understand the affordances of synthetic worlds, including the verbal and nonverbal communication opportunities Second Life offers, how students use these and their impact on the interaction concerning the task given to students.

Keywords synthetic worlds; multimodality; nonverbal communication; CLIL (Content and Language Integrated Learning) 


\section{Introduction}

While the use of online three-dimensional synthetic worlds or virtual worlds for social networking and entertainment purposes is well-established, their use in education contexts is developing (de Freitas, 2006; Falloon, 2010). In the language-learning domain, interest is emerging in this type of environment. Research to date concerning language learning in synthetic worlds has shown that these environments may reduce student apprehension (Schwienhorst, 2002), increase students' sense of social presence and community (Ornberg, 2003; Nowak \& Biocca, 2004) and favour collaborative learning (Henderson, Huang, Grant, \& Henderson, 2009; Dalgarno \& Lee, 2010).

Peterson (2010) suggests that the beneficial aspects of interaction in synthetic worlds are reinforced by the presence of avatars. Avatars are semi-autonomous agents represented in the digital space which can perform actions when commanded by the user (Peachey, Gillen, Livingston \& Smith-Robbins, 2010). They can display a range of nonverbal communication acts. In non computer-mediated communication contexts, nonverbal acts play important roles in communication (Kendon, 1982). Research suggests nonverbal and verbal acts of communication are part of a single system with the same underlying mental processes (McNeill, 2000). Presently there is an increased interest in the role such acts play in second language acquisition (see McCafferty \& Stam, 2008). Increasingly, studies show the importance of nonverbal communication for second-language learners (Gullberg, 2012).

This study of verbal and nonverbal communication in Second Life (SL) builds upon our previous work to understand multimodal communication structures through learner participation and learning practices (Vetter \& Chanier, 2006; Ciekanski \& Chanier, 2008). The 
study extends our research to a three-dimensional learning environment and incorporates kinesic acts within the nonverbal mode.

First, we provide a methodological framework for the study of communication acts in synthetic worlds. We offer a classification of verbal and nonverbal acts in the synthetic world SL, outlining connections between verbal and nonverbal communication acts built into the environment. Secondly, we apply this methodological framework to a course in SL which formed part of the European project ${ }^{1} \mathrm{ARCHI} 21$, where a Content and Language Integrated Learning (CLIL) approach was chosen for students of Architecture. We present our data analysis from the experimentation designed around this course. This experimentation explored whether nonverbal communication acts are autonomous in SL or whether interaction between verbal and nonverbal communication acts exists; and whether the nonverbal acts of communication play the same role in the synthetic world as in the first world.

The rationale behind our study is that evaluation of potential benefits of the SL environment for language learning and teaching requires a deep understanding of the affordances of this environment. This includes i) understanding the communication modalities SL offers; ii) how students use these; iii) their impact on interaction, and iv) studying such questions within a pre-defined methodological framework.

\footnotetext{
${ }^{1}$ Funded by the European Commission as a part of the Education and Culture Lifelong Learning Programme. In 2011 the consortium partners were the Ecole Nationale Supérieure d'Architecture de Paris-Malaquais (ENSAPM), Université Blaise Pascal (UBP), The Open University, the University of Ljubljana, Aalborg University and the University of Southampton.
} 


\section{A methodological framework defining verbal and nonverbal acts in}

\section{the synthetic world Second Life}

Although a dominant focus of research in Language Sciences was verbal communication, the relationship between verbal and nonverbal communication recently stimulated research in Second Language Acquisition (SLA) (McCafferty \& Stam, 2008). This research has concentrated on the nonverbal categories of proxemics understood as the individual use of space to communicate and how this impacts on the behaviour of the individuals involved and kinesics; "the study of the body's physical movement" (Lessikar, 2000:549). Within kinesics, the majority of research concerns the influence of gesture on SLA. The domain of computer supported collaborative work has also investigated the relationships between verbal and nonverbal communication acts and the role of such relationships for collaboration (Kraut, Fussell \& Seigel, 2003; Fraser, 2000). The above studies suggest relationships between verbal and nonverbal communication and the role of nonverbal communication in SLA and in collaborative activities as significant. Synthetic worlds introduce the nonverbal communication mode into computer-mediated language learning. This exciting possibility for collaborative distance language learning remains largely unexplored

The SL environment supports multiple modes of communication which can be employed in interaction to construct discourse. Specifically, nonverbal and verbal modes offer several modalities for communication. Here we propose a classification of these modalities, illustrating relationships between the modes and modalities built into the environment and highlighting how these differ to face-to-face environments. Initially identifying possible 
communication acts in our framework permits us to develop a method for coding and transcribing screen recordings to analyse learner participation and multimodal practices.

\subsection{Verbal mode}

\section{Verbal modalities in SL akin to face-to-face ones}

Oral communication occurs through various synchronous modalities. The public audio channel, allowing "proximity transmission" (Wadley\& Gibbs, 2010:188), enables users to converse within a 60-metre radius. This modality takes spatial proximity and orientation of users into consideration. Another user's voice becomes louder if the avatars are facing each other and when the proximity between users decreases.

\section{New verbal modalities}

A second audio modality is the group audio or "radio transmission" (Wadley\& Gibbs, 2010:188). This allows communication between members of a common group who are spatially separated. A one-to-one, private audio channel, also allows users to communicate verbally without being in proximal contact through their avatars. These latter modalities offer new possibilities for language learning not available in face-to-face classrooms, where oral interaction necessitates visual contact with interlocutors.

Written communication in SL differs to face-to-face pedagogical communication, where synchronous written communication is predominantly unidirectional through the teacher using the board. Written communication acts in the synthetic world may be synchronous or asynchronous and are multidirectional. Different users can communicate with other users by simultaneously using several written modalities. 
The synchronous public text chat can be used simultaneously by users and read by avatars within a 20-metre proxemic range. Secondly, a group text chat feature allows communication within the same group at arbitrary virtual locations. Finally, an instant messaging feature for synchronous and asynchronous communication, allows users to communicate, no matter where they are, inworld or offline. The latter two features can be used in parallel with the public text chat.

\subsection{Nonverbal mode}

Some authors have divided nonverbal communication in SL into user-generated and computer-generated acts (Antonijevic, 2008), also described as rhetorical and non-rhetorical nonverbal communication (Verhulsdonck \& Morie, 2009). A user-generated nonverbal act involves a user consciously selecting an act of nonverbal communication and deliberately performing this act. Computer-generated acts, however, are predefined in the system and the user does not deliberately choose to display these. In our methodological framework, we prefer to sub-divide the categories of nonverbal communication by their communicative act rather than with reference to how they are encoded by the user and synthetic world. We will refer to the modalities of proxemics, kinesics and avatar appearance. Figure 1 shows our classification of nonverbal acts identified in SL. Full details of this classification are discussed in Wigham \& Chanier, 2011. In this paper, we exemplify a few of these categories. 


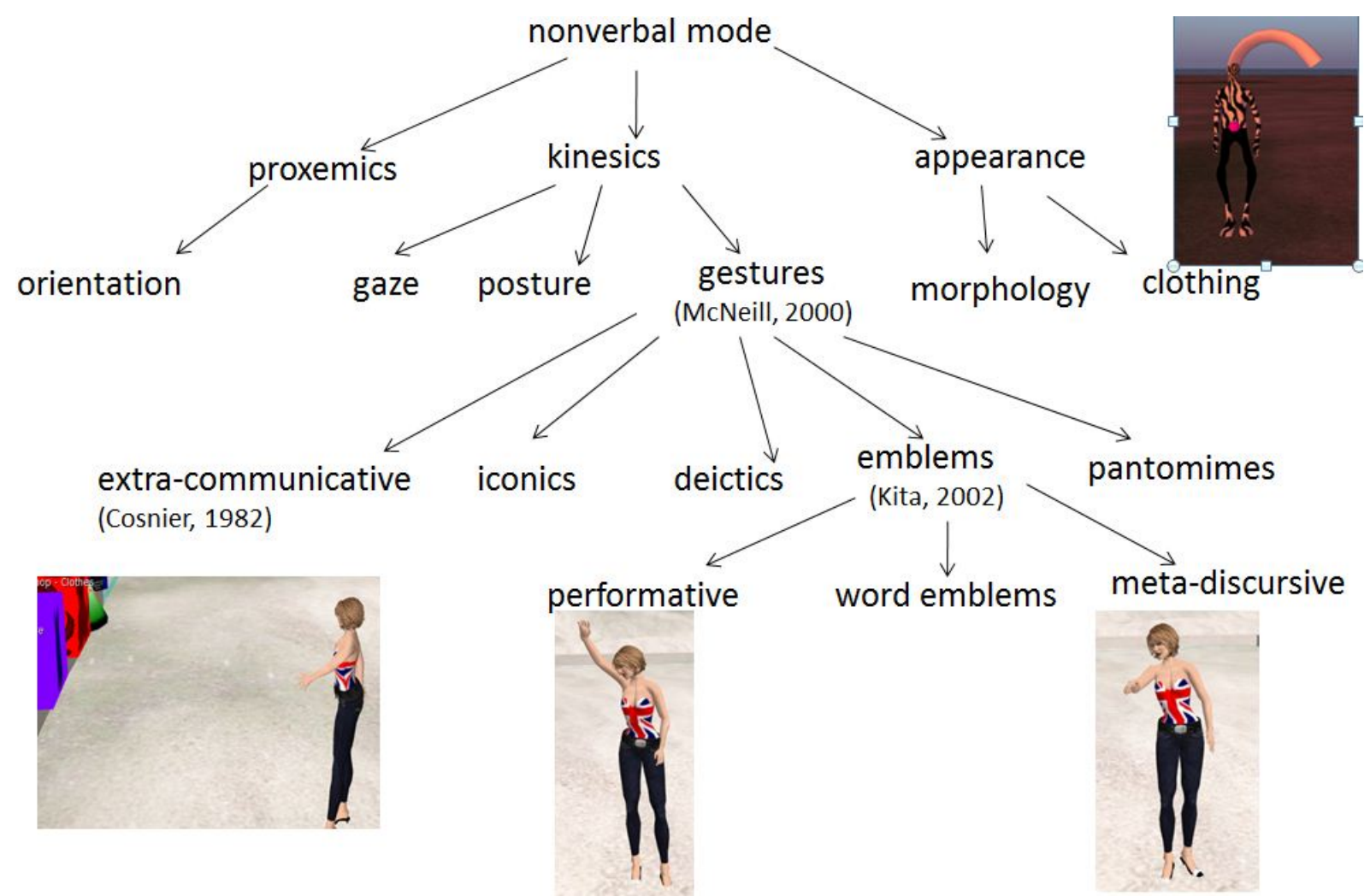

Fig. 1. Nonverbal communication in SL

\section{Proxemic acts}

The range of proxemic acts available to SL users includes choosing to move their avatar, i.e. making the avatar walk, run or fly; orientating their avatar and positioning their avatar with respect to others. Because proxemic acts in SL are user-controlled, we must consider their importance for interaction. Indeed, proxemic nonverbal communication has been the focus of various studies in different synthetic worlds (Jeffrey \& Mark, 1998; Yee, Bailenson, Urbanek, Chang \& Merget, 2004). This research shows that the way people move and approach others and their positioning of avatars in relation to others is affected by how space in the synthetic world is perceived. Avatar gender also influences the proxemic space users choose between interacting avatars.

In SL, we note the wish of the synthetic-world designers to associate proxemic acts with verbal communication, particularly in association with the proxemic dimension of voice 
loudness. Firstly, in the written communication, a user may increase or decrease the distance at which a message can be read publicly by using the whisper or shout function. This is displayed nonverbally through a pantomime gesture. Secondly, as previously mentioned, the audio channel takes the spatial proximity and orientation of users into consideration.

\section{Kinesic acts}

The kinesic act of gaze is a predefined cue having, with relation to the verbal mode and the nonverbal category of proxemics, the function of mimicking interactional synchrony. When an avatar is moved in a certain direction, nearby avatars' heads automatically turn to this direction, imitating the proxemic coordination of movements between interlocutors and complementing the verbal communication. Another predefined gaze movement is an automatic 'lookat feature' whereby avatars gaze at any avatar joining their group. Ventrella (2011) underlines the relationship between gaze acts and verbal acts in SL: avatars respond to another avatar's written communication in the public chat channel by turning their gaze towards the avatar who generated the written communication. Ventrella (2011) suggests these subconscious social acts reflective of face-to-face communication help users feel acknowledged and welcome.

The kinesic act of posture is also incorporated into SL. When there is a significant pause in written or oral communication, the user's inactivity in the verbal mode automatically sets the posture of his/her avatar to that of a 'spectator': "the avatar slumps over forward as if to fall asleep while standing" (Ventrella, 2011:85).

Deictic acts are encoded in SL when a user touches or manipulates a media object in the synthetic world. There is no distinction between the deictic gesture to show that an avatar is 
touching an object or if $\mathrm{s} / \mathrm{he}$ is manipulating or editing the object. For example, changing the size, colour or script of objects.

Kendon (1982) defines pantomime gestures as movements of the hands and arms always in the visual description of an action or an object. In SL numerous avatar animations portray the avatar as visually imitating an action. These include the avatar animations of crying, smoking, and typing (see Figure 2.)
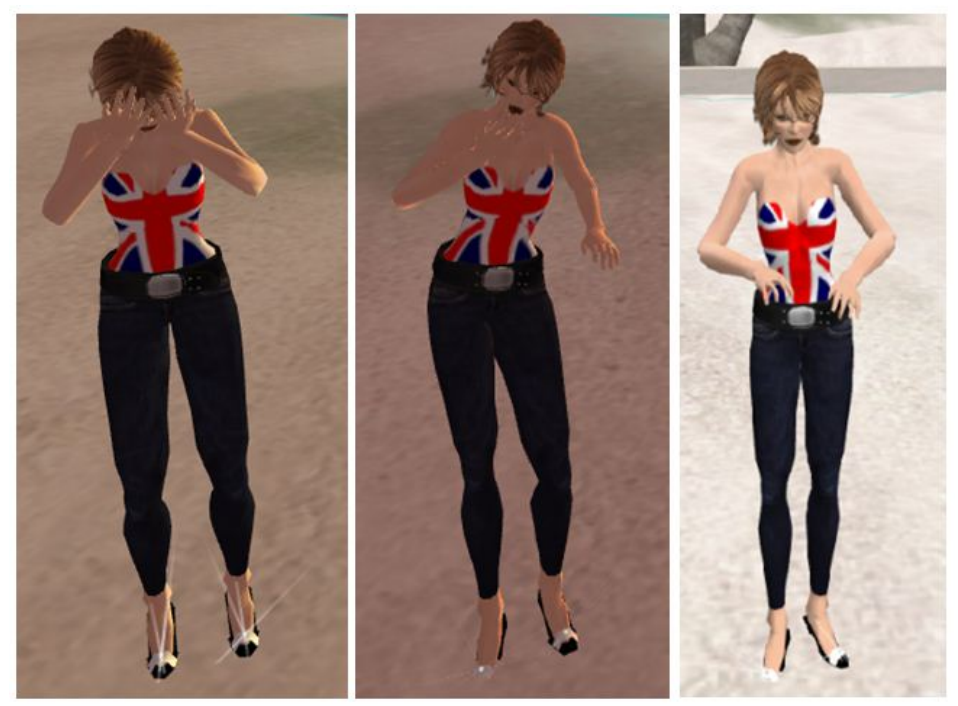

Fig. 2. Examples of avatar pantomimes for crying, smoking and typing

Links between pantomimes and verbal modalities occur: users can make their avatar perform pantomimes by typing a command in the public text chat window and when users communicate in the written mode, their avatars portray the typing pantomime. If users decide to use the whisper or shout features in the written mode, their avatars also perform pantomimes complementing the written communication.

SL also includes examples of emblems. These cultural gestures often replace verbal communication, despite the possibility to translate the gestures by a word or an expression. We will not develop them here. 
Finally, iconic gestures, described by McNeill (2000) as representations of an action or object, are found in SL. They have a very direct relationship with the semantic content of a verbal utterance showing physical, concrete items. In SL examples include gestures to illustrate scissors and a sheet of paper. Indicators of emotional states are also expressed through iconic gestures in SL, in contrast to face-to-face communication which uses facial expressions.

\section{Avatar appearance}

In SL, users may change their avatar's morphology and clothing. This type of nonverbal communication is not the focus of this paper. However, during our study we noticed that when participants felt at ease, efficiently manipulating the learning environment (to which they were almost all newcomers), they quickly changed their avatars' appearance to become less based on human morphology (see Figure 3), continuously used pantomime gestures or scripting their avatars appearance. We are currently undertaking research to understand the impact of such changes of appearance on the students' interaction and discourse.

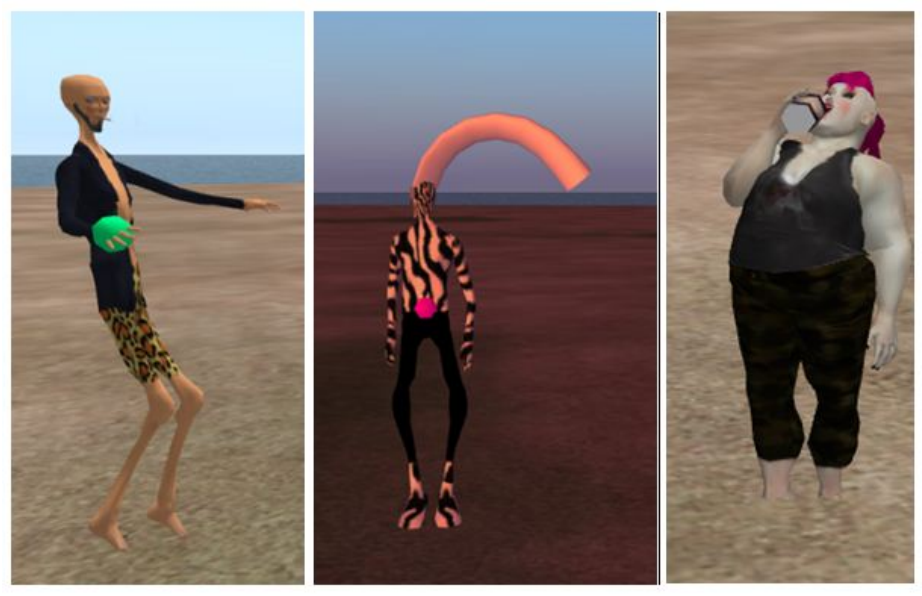

Fig. 3. Avatar appearances 


\section{The ARCH121 course and its research protocol}

\subsection{The ARCHI21 'Building Fragile Spaces' course and participants}

The pedagogical scenario of this study is the 'Building Fragile Spaces' course which ran in February 2011 and formed the first work package of the ARCHI21project. A dual-focused approach to language learning is at the core of this project: the subject content being architecture and the languages (L2) French and English. CLIL aims to eliminate "the artificial separation between language instruction and subject matter classes" (Brinton, Snow \& Wesche, 2008:2) by teaching non-language subjects through a foreign, second or other additional language (Marsh, Marsland, \& Stenberg, 2001). Providing curriculum content in a L2 can lead to increased subject knowledge and enhanced language proficiency (DaltonPuffer, 2007; Coyle et al., 2010).

The course was a five-day intensive design studio. This is a typical face-to-face set up within architectural education: professionals work with small student groups, over a short period, developing design ideas. The CLIL pedagogical scenario for the course was designed by architecture teachers from the ENSAPM school and language teachers from our university (UBP). The course's architectural focus was the design and construction of an immersive SL environment for the ARCHI21 project. This was based on the belief that 3D synthetic worlds are an exciting new design field for architectural experimentation. They allow the design of innovative architectural projects between multiple users in the same space, providing opportunities for collaboration. They also allow building to be visualised in new and effective ways.

The course had the goal of developing working models for spatial archetypes, landscapes and identity. The rationale behind the development of $L 2$ skills was the future need for the 
students to be able to work abroad and to collaborate with foreign architects. Architecture teachers worked face-to-face with students, constantly switching between French (which was a L2 for half of the students) and English. Language tutors, who had no architectural subject knowledge, worked at a distance.

'Building Fragile Spaces' involved eight female and nine male students, aged between 21 and 25 years. Students ranged from first year undergraduates to second year Masters' students. French was the mother tongue of nine of the seventeen students. The mother tongues of the remaining eight were Spanish, Chinese, Italian, Korean and Arabic.

The participants were divided into four workgroups. This division was thematic and linguistic: each workgroup received a different architectural brief and had a dominant second language (see Table 1). Two students had previously used SL.

Table 1 Workgroups

\begin{tabular}{|l|l|l|}
\hline Workgroup & Target language & Target language level (CEFR) \\
\hline avatars (GA) & French (FLE) & A2-B1 \\
\hline land+scapes (GL) & French (FLE) & A2-B1 \\
\hline (e)spaces (GE) & English (EFL) & B1-B2 \\
\hline scenario (GS) & English (EFL) & B1-B2 \\
\hline
\end{tabular}

Following the CLIL approach, all the language activities closely assisted architectural ones.

The pedagogical scenario for the language activities included introductory sessions to SL, focusing on the communication tools and how to move within the environment; introductory sessions to building collaboratively in the synthetic world; and a series of group reflective sessions inworld (see figures $4 a$ and $4 b$ ). This paper focuses on one collaborative building session completed by the participants in English or in French depending on the target language of their workgroup. 


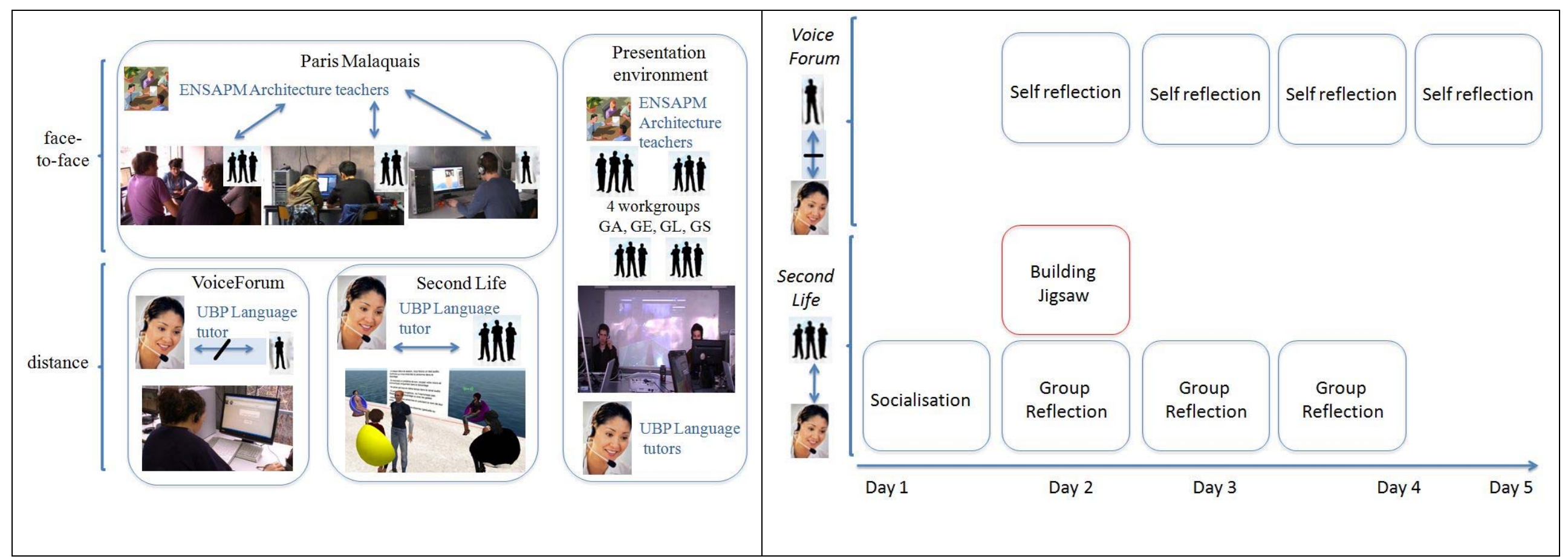

Fig. 4. a) course environments; b) distance language activities 


\subsection{The Buildjig activity}

The activity 'Buildjig', on which this study focuses, is an introductory building activity (see figure $4 b$ ) in the target language. The objectives were two-fold:

- Architectural design learning objectives: Introduce students to building techniques; assemble a presentation kiosk designed by architecture tutors as an example of how students could present their project work.

- L2 learning objectives: Develop communication techniques in the L2 concerning the referencing of objects; practise oral skills

So as to encourage collaboration and interaction, the activity was designed to incorporate a two-way information gap. It employed one of the six learnings suggested by Lim (2009:7) for inworld curricular design in synthetic worlds: "learning by building." The activity required the exchange of information between students, each of whom possessed information unknown to the other participant but of importance in solving the problem.

Students worked in subgroups for the activity. One student was designated as the 'helper'; the other as the 'worker.' The helper directed the worker in assembling the kiosk from a set of objects. S/he was not allowed to manipulate the objects him/herself (see Figure 5). The helper had a two-dimensional representation of the final kiosk. The worker, on the other hand, did not have the final shape of the kiosk but the three three-dimensional objects from which to construct the kiosk. To solve the problem, students had to exchange information about the two-dimensional characteristics of the objects in comparison to their threedimensional characteristics in-world. The activity demanded nonverbal interaction with the 
objects in the environment, in terms of the building actions, and verbal interaction between the students in order for successful activity completion.

Including the language tutor's presentation of the activity, and a short group debriefing, the activity lasted 50 minutes. The activity was the second time that the students met with the language tutors inworld.

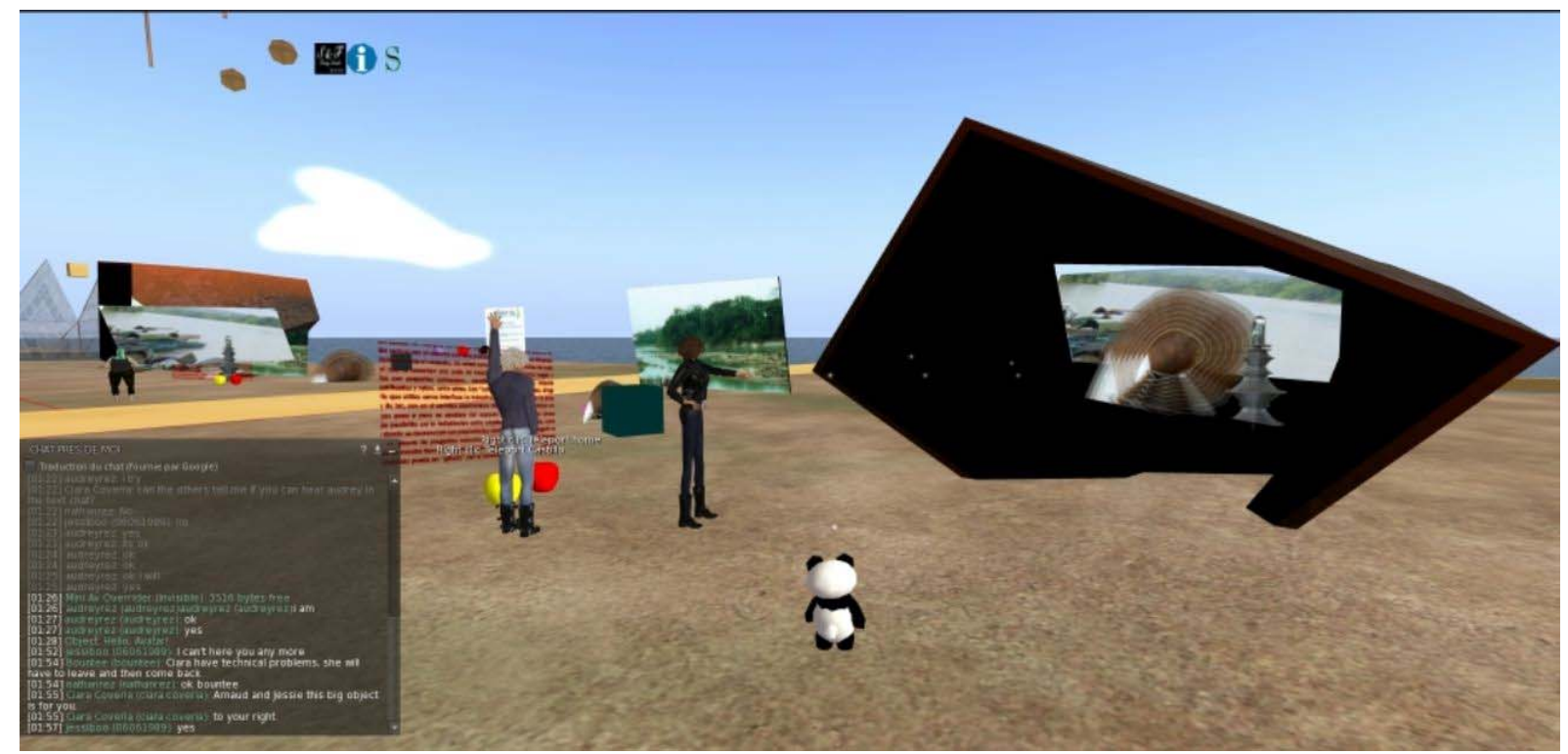

Fig. 5. Helper and worker in the Buildjig activity (the bear avatar is the researcher recording their actions)

\subsection{Research protocol}

Researchers, present inworld in the form of small animal avatars (see figure 5), observed the workgroups and recorded screen and audio output. The role they took was that of 'observer as participant' (Gold, 1958) as they had minimal involvement in the setting being studied. A small animal figure was chosen because the researchers believed that the students would be less likely to address an avatar with a non-corporeal body and, thus, the researcher's avatar would be as unobtrusive as possible. 
Pre-course and post-course questionnaires were administrated using an online survey tool. These were analysed using a spreadsheet application. Semi-directive online interviews were also conducted with five students following the course. The students were selected on a volunteer basis but we ensured that at least one student from each workgroup was interviewed. The learner interaction data as well as the learning design and research protocol were structured into an open-access LEarning and TEaching corpus (Chanier, Wigham \& Saddour, 2011).

Here, we consider four screen recordings of the buildjig activity with subgroups of the four workgroups. The two ESL subgroups were composed of pairs, whilst the FLE subgroups were composed of three students with one 'helper' and two 'workers' due to the uneven number of participants on the course. The screen recordings, each 50 minutes in length, include the activity introduction and a debriefing activity. Here, we focus solely on the building activity itself. For each subgroup, the screen recording lasted, on average, 25 minutes.

Identifying communication acts in SL allowed the development of a method for coding and transcribing screen recordings of interactions. Building upon previous research (Ciekanski \& Chanier, 2008) and methodology applied to LEarning and TEaching corpora (LETEC) (Mulce, 2010), each modality and communication act was identified. Thus, acts were defined and each act tagged (see Table 2). 
Table 2 Data analysis codes for different acts

\begin{tabular}{|l|l|}
\hline tpa & audio \\
\hline tpc & text chat \\
\hline sil & silence \\
\hline es & entering or exiting environment \\
\hline mvt & movement \\
\hline kin & kinesic \\
\hline prod & production \\
\hline
\end{tabular}

Two scales of analysis were adopted. On a macro level, the qualitative data analysis software Nvivo was used to i) annotate screen recordings qualitatively and ii) code users' verbal and nonverbal acts. This allowed the balance between the uses of different modalities to be analysed. To annotate the verbal and nonverbal acts of the participants, each act was identified by type; by actor; by a time in the audio-track, which was synchronised with the screen recording; and by the duration of the act (see Table 2). Any silence in the audio track was coded i) to show the continuity of the audio signal and, therefore, the total time that students had available for verbal interaction and ii) to place nonverbal acts on the same time scale, permitting us to analyse relationships between acts of different types during the data analysis.

On a micro level, the qualitative data analysis software was used to code the verbal acts which included a reference to an object by type of reference made. Examples 1 and 2 show the transcription of two verbal acts, in which a reference to an object was coded (in bold). In (1), the reference was coded under 'reference by colour'. (2) was coded as 'reference by description'. 


\section{$(1)$}

[mm:ss, quentinrez, tpa] I think it's it's easier to err just err pick up the + the black

(2)

[mm:ss, romeorez, tpa] it seems like two squares+ two twisted squares

Full transcription details are detailed and exemplified in Saddour, Wigham \& Chanier (2011). In brief, our transcription methods highlight the start time of each turn in the format minutes:seconds, the actor's code and the type of communication act, shown by its code. Pauses which are less than three seconds are shown by the symbol + which represents one second. Longer pauses are coded as a separate turn with the code 'sil' for silence. Overlap within a verbal turn is shown by (actor_code: transcription). For the nonverbal acts of movement, kinesics and production, a description of the nonverbal act is given, based upon a grid elaborated during the transcription process.

Having defined our framework, we can now quantitatively and qualitatively study how the verbal and nonverbal modes of communication are used in the synthetic world SL to understand i) whether nonverbal communication acts are autonomous in SL or whether interaction between verbal and nonverbal communication exists and ii) whether nonverbal acts of communication play the same role in the synthetic world as they do in the first world.

\section{Analysis}

\subsection{Activity achievement}

The building jigsaw activity was the second time that the students met inworld with the language tutors. Although the building involved in the activity was beyond the language tutors' abilities, who were not sure whether they could complete the building task alone, our data shows that the activity was pitched at the level of the students. In a post questionnaire 
when asked whether it was too difficult to communicate with their partner during the activity, on a scale from five (totally agree) to one (don't agree at all) the students rated the activity at three (no opinion). Although none of the groups fully completed the activity within the allocated time, the work of groups GE and GS strongly resembled the finished design. GA, after taking some time to get into the activity had started the task and, after the activity, decided to remain inworld to finish their work. The building work of GL, on the other hand, had barely commenced; a student in the worker role trying to build the kiosk by himself.

\subsection{Floor space related to verbal acts}

Analysis of the use of the verbal and nonverbal modes was conducted with reference to floor space. We consider the floor space as the sum of the total length of all acts within a specific mode for an individual actor with reference to the total length of all acts communicated in this mode (including silence for the verbal mode) by all actors present. Figure 6 shows the distribution of public audio floor space within the groups, according to participants' roles.

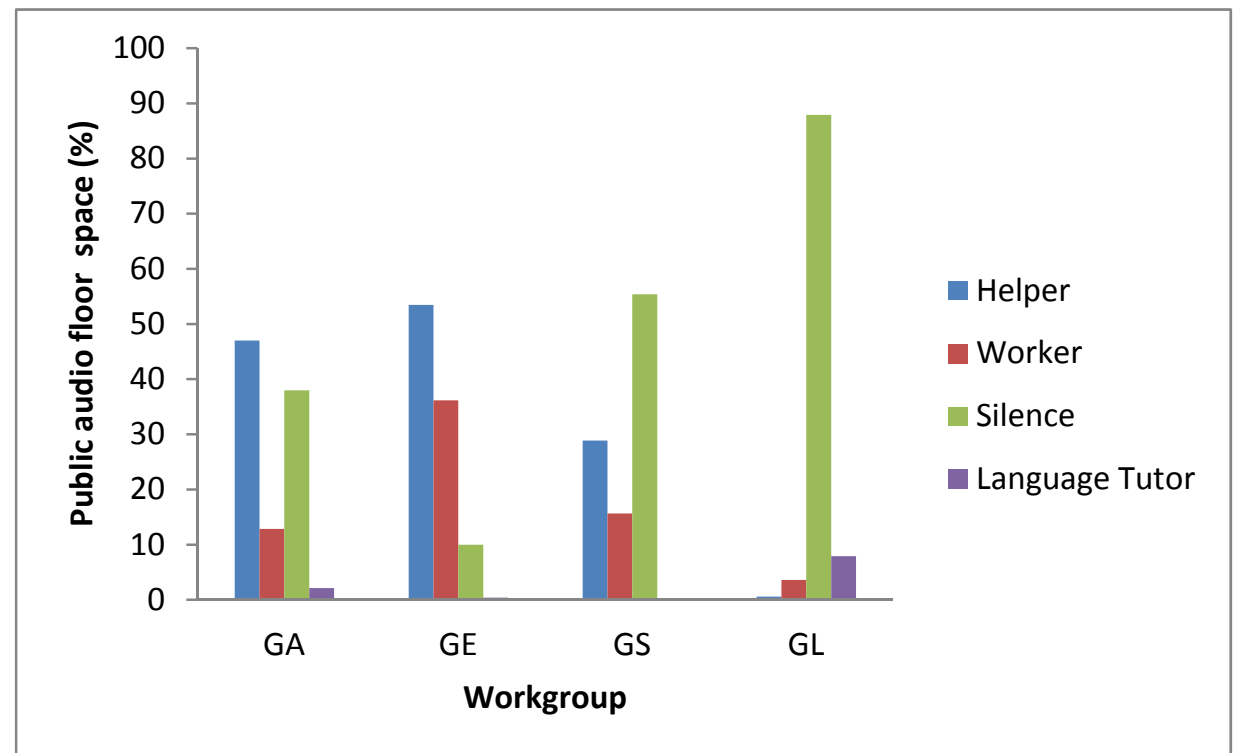

Fig. 6. Distribution of public audio floor space with respect to role during activity and workgroup 
In GE, the students' verbal (audio only) acts accounted for $89.62 \%$ of the possible verbal floor space, compared to $59.87 \%$ for GA, $44.51 \%$ for GS and $4.17 \%$ for GL. In the two groups in which the students accounted for the majority of all verbal acts (GA and GE; the two ESL groups), the language tutor accounted for less than $2.2 \%$ of the verbal communication. This is significantly different for the FLE groups. For group GS the language tutor accounted for $0.11 \%$ of the total verbal communication, and in group GL the tutor occupied nearly double the amount of verbal floor space compared to that of the students ( $7.91 \%$ compared to $4.17 \%)$

Our results show verbal floor space was not balanced between students in the roles of helper and worker. In groups GA, GE and GS the helper occupied, on average, $21.56 \%$ more of the verbal floor space than the workers in each group.

\section{Text chat modality}

The group text chat modality was infrequently employed in the verbal mode, accounting for only 31 acts compared to 781 verbal acts in the public audio modality. One possible reason for a reliance on the audio modality is the nature of the activity: speaking frees the participants' hands, allowing them to communicate whilst carrying out the building actions which require the use of the computer mouse and keyboard.

The group GL utilised the public text chat modality more than any other group with 23 acts in total. This is of interest when compared to the use of the public audio modality. Concerning the latter, the actors in this group performed 38 verbal acts, of which 31 were performed by the language tutor. In this group, the student in the helper role [wuhuasha] continuously placed his avatar at a considerable distance from the other students. One interpretation of the choice of modalities is that students adapted their communication 
strategies to the environment: there is an emergent understanding that as the distance between avatars increases, the users can no longer 'hear' each other because the public audio channel takes users' proximity into account.

Group GL's advancement of the object construction was near none compared to other groups. This may be explained by their reliance on text chat which did not allow students to manipulate objects and communicate simultaneously. Another interpretation is that the proxemic distance between avatars impacted on the students' involvement in the activity. The majority of the communication acts did not concern the activity per se but consisted of the workers trying to establish communication with the helper and the language tutor (tfrez1) encouraging students to move into a closer task space so as to encourage audio communication (see 3 and 4).

(3)

[tpc, zeinarez, 02:01]: wuhuasha

(4)

[tpc, tfrez1, 02:04]: wuhuasha vous pouvez vous déplacer (wuhuasha can you move ?)

The verbal acts performed by wuhuasha occurred when the language tutor placed her avatar near to the student's avatar. When the tutor moved physically away, wuhuasha had no further participation in the communicative exchange. This suggests that, as in the first world, distance matters for communication purposes.

We note that wuhuasha, at A2 level, was the weakest student of the FLE groups. Instances which may be clear for students in face-to-face environments may indeed require extra 'effort' in synthetic worlds. Students, particularly at lower levels may have difficulty in "performing" their avatar (Verhulsdonck \& Morie, 2009:6) whilst focussing on the activity and their language production. Wuhuasha had difficulties managing the different facets of SL 
and did not recognise the importance of proxemic distance in the environment's

communicative rules. It appears important to stress to learners the need to place their avatars proxemically near to each other so as to encourage verbal communication (and specifically audio communication). This, in order to avoid communication difficulties and breakdown in collaboration.

\subsection{Floor space related to nonverbal acts}

We now focus on the nonverbal communication mode and floor space distribution within this mode. Apart frrom GS, the nonverbal floor space distribution between the students in the helper-worker roles was considerably different (see Figure 7). The language tutors' usage of nonverbal communication occupied between $3.49 \%$ and $10.98 \%$ of the floor space within each group.

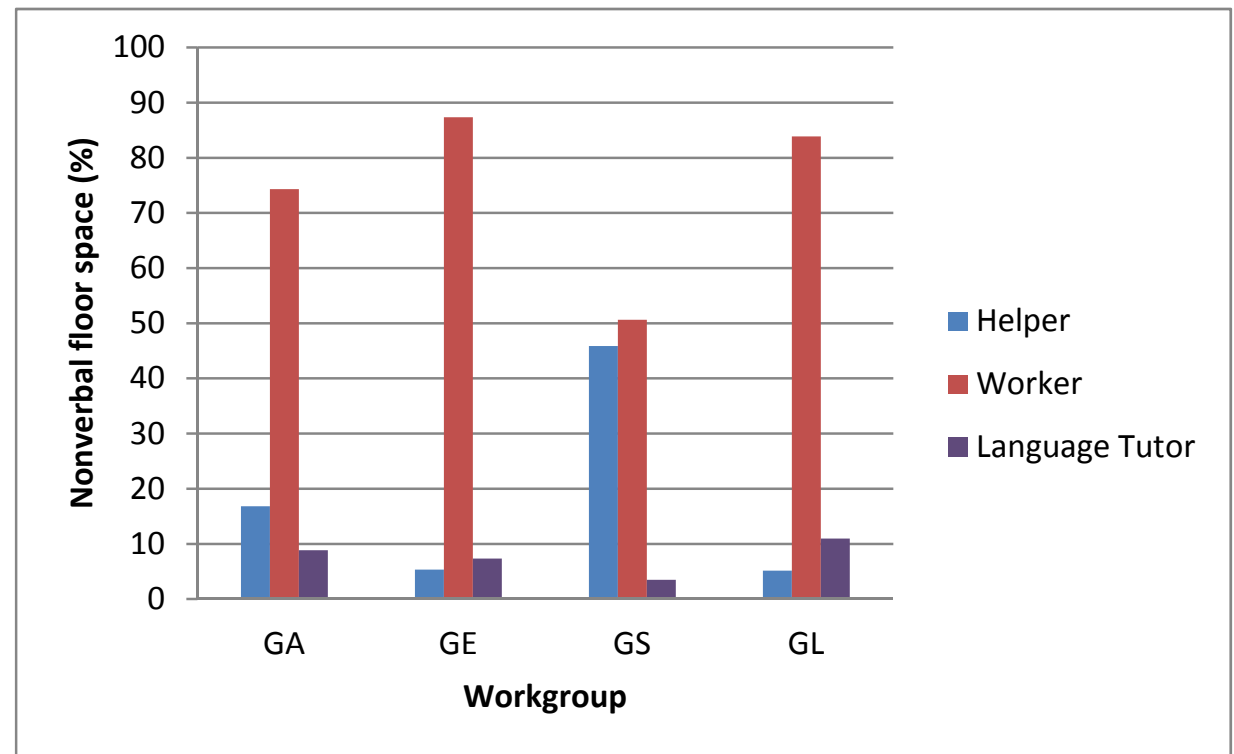

Fig. 7. Distribution of nonverbal floor space with respect to role during activity and workgroup

Deictic gestures accounted for $60 \%$ of nonverbal communication in the four workgroups (see Figure 8 ). $78.17 \%$ of deictic gestures were performed by students in the worker role. This predominance can be explained by the nature of the activity: interaction with objects in SL, e.g. modifying the position of an object, requires the avatar to touch the object. The 22 
environment portrays this as a pointing gesture. No iconic gestures or emblems were used by the actors in the activity studied. However, pantomimes of typing, dancing and eating were present.

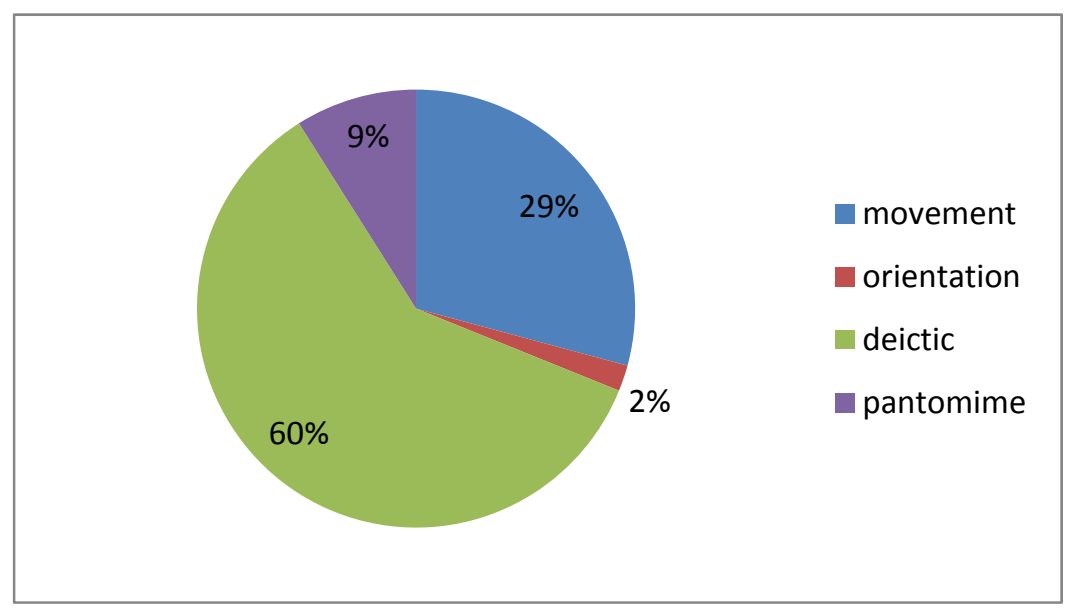

Fig. 8. Distribution of nonverbal communication cues identified for the four workgroups

In all four workgroups, students in the worker role occupied more nonverbal than audio floor space (see Figure 9). The results for the students in the helper role were more varied. In the two FLE groups, GA and GL, the helpers occupied less audio floor space than the workers and occupied more nonverbal floor space than audio floor space. In the ESL group GE, the helper occupied significantly more of the audio floor space than the nonverbal floor space whilst in the GS group the helper's communication was more evenly distributed between the two modes. Due to the nature of the helper-worker roles, the modalities the students used were organised differently. 


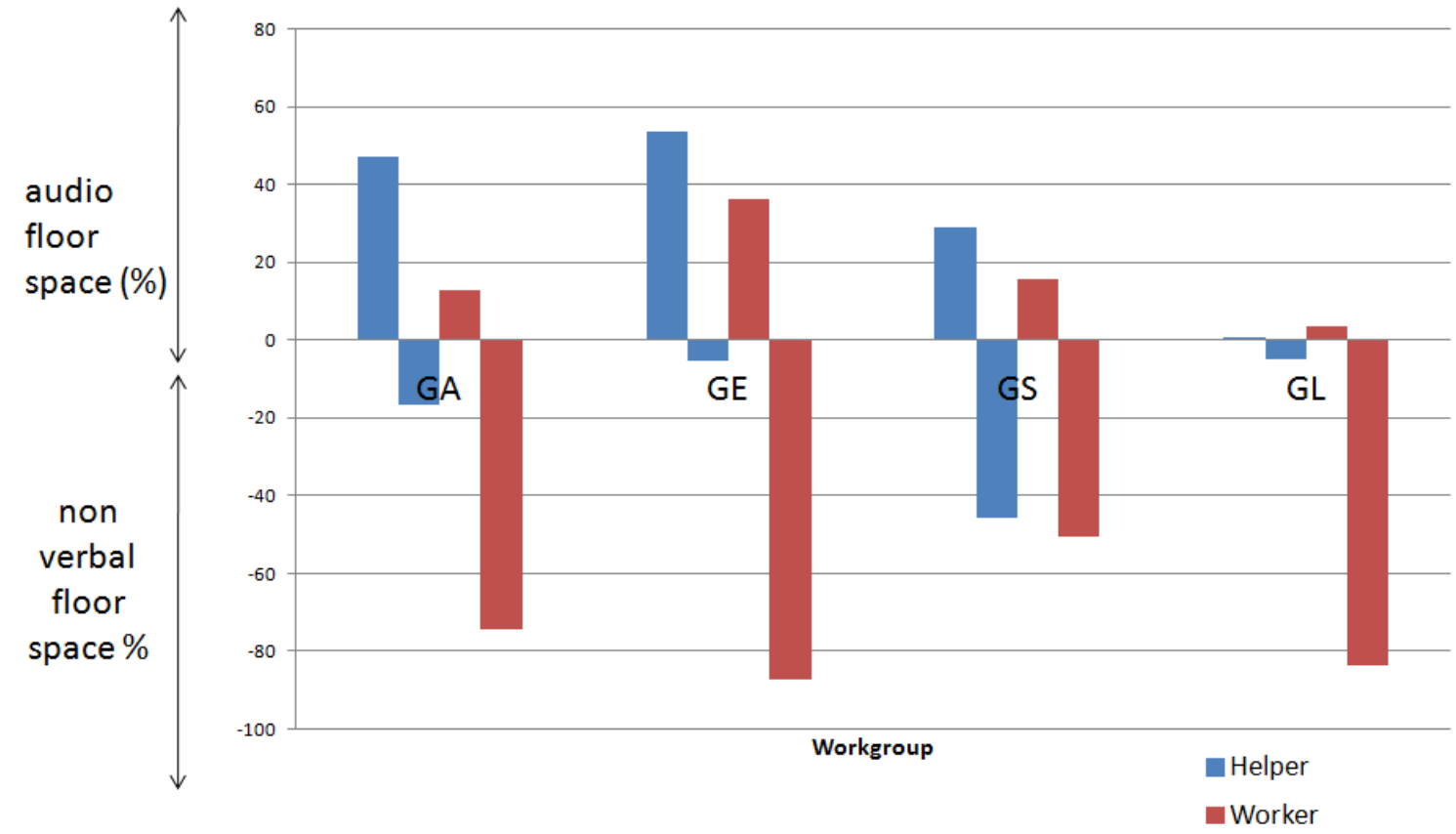

Fig. 9. Distribution of nonverbal and audio floor space

The dominance of deictic gestures in the nonverbal communication is of interest. No verbal acts draw a counterpart's attention to such a gesture and verbal deictic references were very infrequently used. They accounted for only $5.16 \%$ of all verbal acts made which included a reference to an object. One possible explanation is that when a worker interacts with an object, if the helper displays both the worker and the object on his computer screen, s/he can ascertain with which object the worker is interacting. Students may not have needed to draw attention to objects through verbal communication because they were always obvious in the nonverbal mode.

Another, more plausible, explanation is that the students preferred verbal references to objects (instead of verbal deictic references) which pertained to more specific characteristics to avoid ambiguity. Although the number of verbal references to objects differed depending on the students' role, both helpers and workers most frequently employed references concerning the object name, the object size or a description of the object (see Table 3). Thus, 
students adapted their communication strategies to the environment: uncertain of their counterpart's view of the environment choosing specific references to objects which lacked ambiguity helped identify and refer to objects quickly and securely.

Table 3 Top categories of verbal acts referencing objects by type and student role with examples

\begin{tabular}{|l|l|l|l|}
\hline $\begin{array}{l}\text { Type of reference to } \\
\text { object made in verbal } \\
\text { act }\end{array}$ & $\begin{array}{l}\text { Example from audio } \\
\text { transcription with coded } \\
\text { part of utterance } \\
\text { underlined }\end{array}$ & $\begin{array}{l}\text { Percentage } \\
\text { of 247 acts } \\
\text { (helpers) } \\
\text { referencing } \\
\text { objects }\end{array}$ & $\begin{array}{l}\text { Percentage } \\
\text { of 134 acts } \\
\text { (workers) } \\
\text { referencing } \\
\text { objects }\end{array}$ \\
\hline name & $\begin{array}{l}\text { the first dome }+ \text { don't } \\
\text { touch don't touch }\end{array}$ & $19.22 \%$ & $4.39 \%$ \\
\hline size & $\begin{array}{l}\text { the big the hole is in front } \\
\text { of us: okay the big is good }\end{array}$ & $13.64 \%$ & $3.06 \%$ \\
\hline description & $\begin{array}{l}\text { it seems like two squarest } \\
\text { two twisted squares }\end{array}$ & $10.10 \%$ & $3.03 \%$ \\
\hline
\end{tabular}

\section{Shared visual space for collaborative activity}

This explanation is strengthened when we consider the acts performed in the nonverbal category of movement. To help object identification, avatar movement, positioning and orientation were frequently employed in parallel with a reference to an object in the verbal mode. Students used the position of an avatar as a static point from which to refer to an object to be identified. This strategy, however, was frequently unsuccessful in identifying the object. In example 5, the student in the helper role refers to an object "in front of us". The worker does not correctly identify this object because his subsequent nonverbal act prompts the helper to tell him "don't touch don't touch the bIG:". The reference is misunderstood by the student. 


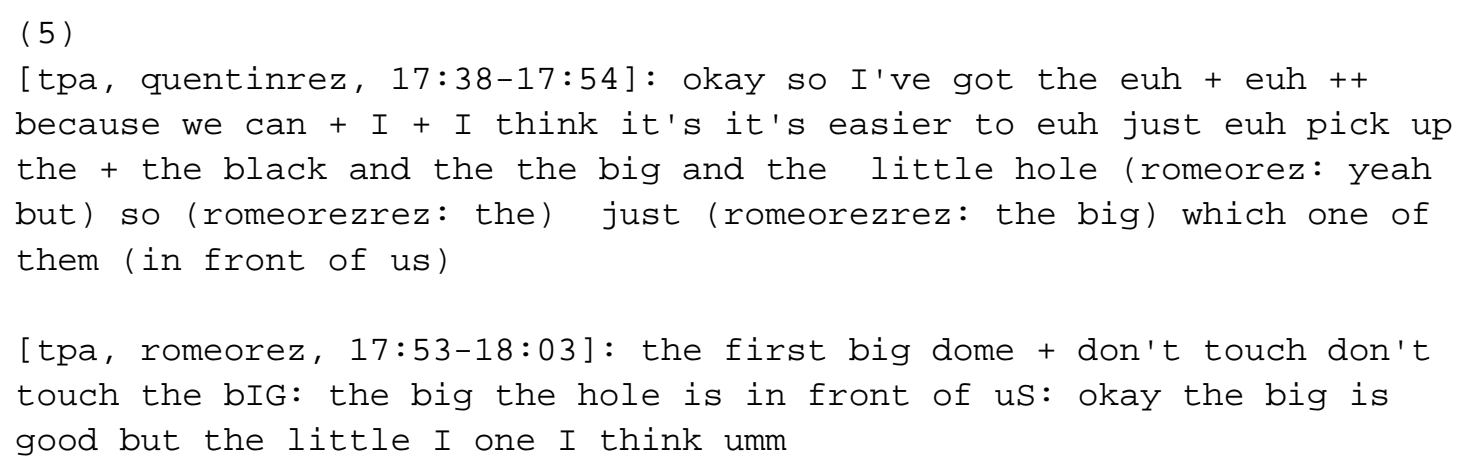

In the post-questionnaire, this student stated that he used the SL camera view nearly all the time. The camera allows users to detach their point of view from the avatar they control, allowing the user to gain multiple perspectives. In a subsequent interview, the student stated that his use of this view had no impact on the interaction for at all times he could clearly hear his partner. However, no students asked their partners, before making a reference to an object in relation to another static point (e.g. the student's avatar,) whether their counterpart was using the camera view or not: the students did not try to establish common ground in terms of their shared visual space before communicating verbal references to objects.

Kraut et al (2003) and Clark \& Krych (2004) argue that in distance collaborative activities participants must have shared visual access to the collaborative activity space so as to help establish deictic references. This is perhaps one of the reasons that students used few deictic references in their verbal communication. We also suggest that this is also true when searching to establish references with reference to the position of an avatar: it appears fundamental that both students are aware of their physical orientation to one another. It is perhaps for this reason that students preferred avatar movement and orientation as a form of reference. 


\section{Language difficulties and nonverbal acts}

Students used avatar movement and orientation to help mark the position of an object. In example 6, the helper specifically decides to position his avatar in the same place in which he wishes the worker to position the object with which the pair is working.

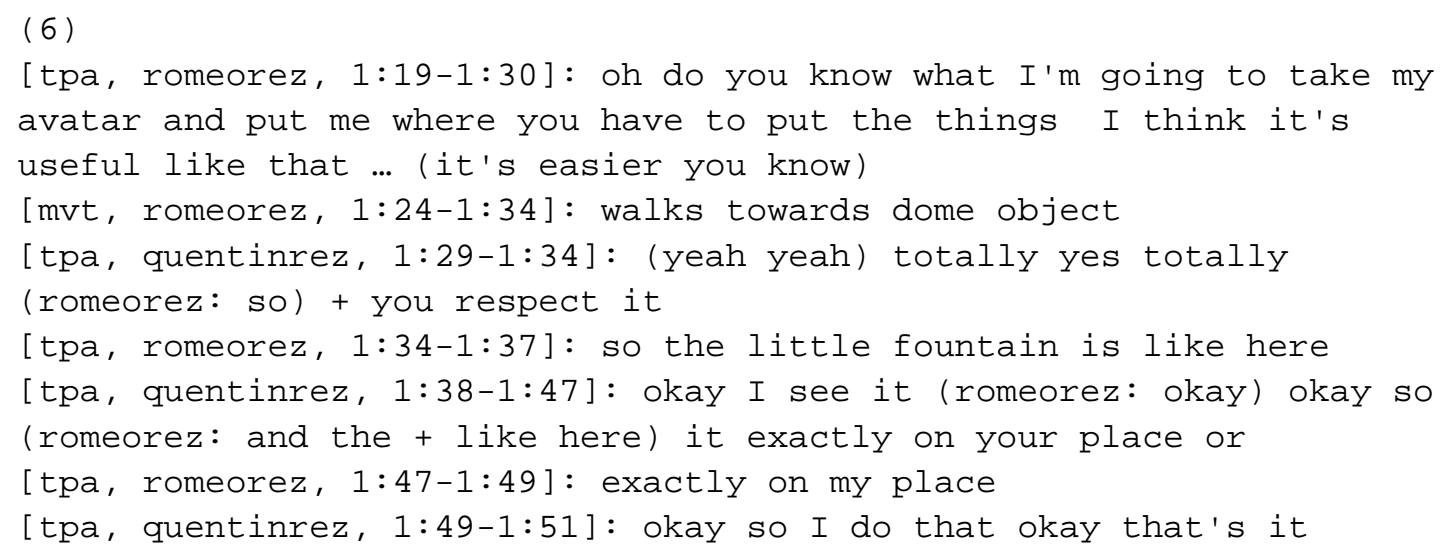

In a post-course interview, of the 'critical-event recall' type, after having viewed the video corresponding to example 6, the student quentinrez described the fact of moving his avatar to where the object had to be placed as a strategy to overcome his poor vocabulary concerning position and direction:

in fact it's because $+l^{\prime} d$ say directions and rotations because we have a very poor vocabulary when we're speaking and try to describe a position or a direction or something to do with orientation in fact that is the specific area where we are really missing lexis + orientation

\section{Ambiguity of verbal deictics and nonverbal acts}

We remark that in all instances when the students decided to adopt, for the first time, the strategy of moving an avatar to refer to an object or to mark the position of an object that it was following a non-successful verbal communication to try to describe the object or how to position the object. 
For example, GA encountered a difficulty in the verbal communication concerning which object was to be manipulated. This difficulty arose because the students were not aware of what was in their partner's field of vision when they used determiner 'cet' (see example 7). When the worker asked a question to try to decipher which object the helper was referring to, the helper decided to move her avatar, running over to the object in question. Thus, in her later verbal communication we can see that she moves from talking about 'cet' to talking about 'celui'. To compensate for the difficulties in knowing what is in her partners' field of vision and not rely on deictic words alone, the student uses nonverbal communication to make explicit her verbal communication. Indeed, at first, the deictic word 'cet' was entirely context dependent. Its meaning could shift and was non-unique. By using nonverbal communication alongside a verbal deictic word the student secures the context for her reference, anchoring the deictic word to a specific object in the environment. We suggest that, because in this situation shared visual access to the collaborative activity space is not guaranteed, that explicitness in the nonverbal communication helps to secure the reference.

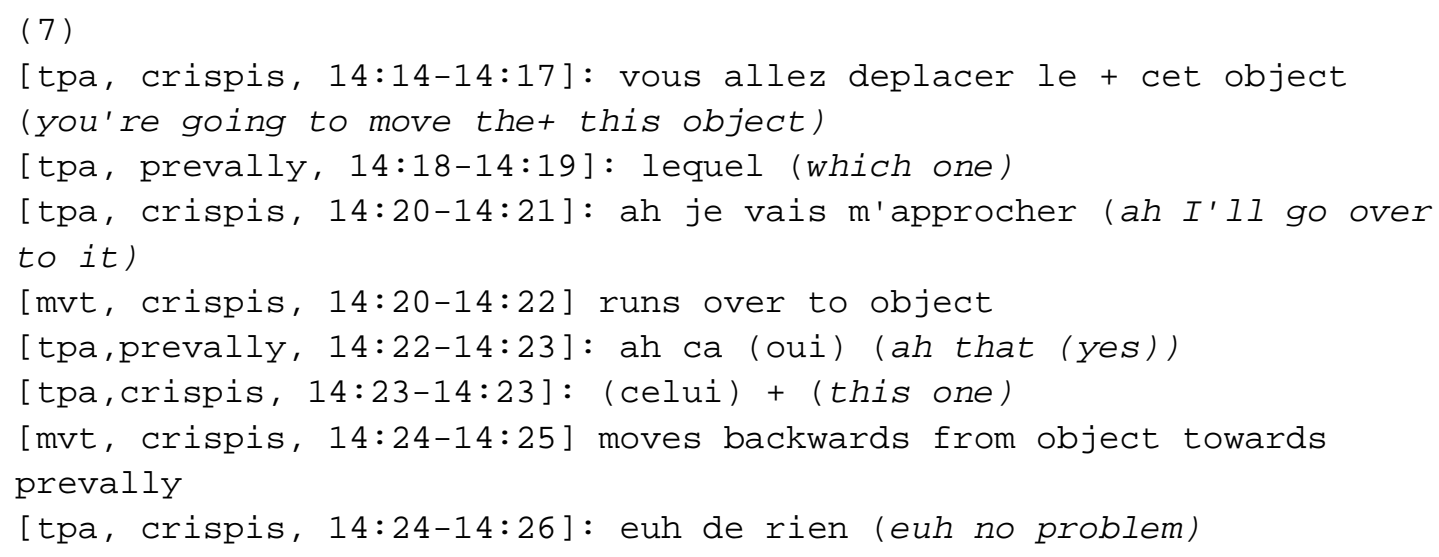

It is interesting to notice that in our post-course questionnaires, 13 of the 16 students who responded, agreed with the statement that "in distance communication situations, being able to communicate through an avatar (-movements, gests, appearance) allows you to engage more in the conversation". 
The numerous examples of the use of avatar movement and positioning to clarify verbal acts and the importance the students attach to this for their communication beg the question as to whether synthetic worlds enable the direct transfer of face-to-face strategies as regards spatial reference to objects. In these examples we note that users must accommodate to the properties of the environment by using nonverbal communication in association with verbal communication or they risk miscommunication and, thus, reduced success in the building activity.

\section{Proxemics and verbal interactions}

The verbal mode was also used in association with the nonverbal mode to organise the proxemic positioning of the students' avatars. We found that students did not instinctively move or orientate their avatars in the formation of groups at the beginning of activities and did not naturally position their avatars to face each other as we believe they would in faceto-face situations. For an example, see Figure 10 in which we can observe an avatar using the oral mode to communicate (indicated by the wave icon) and another avatar replying by written communication. These avatars are interacting; however, they have their backs to each other.

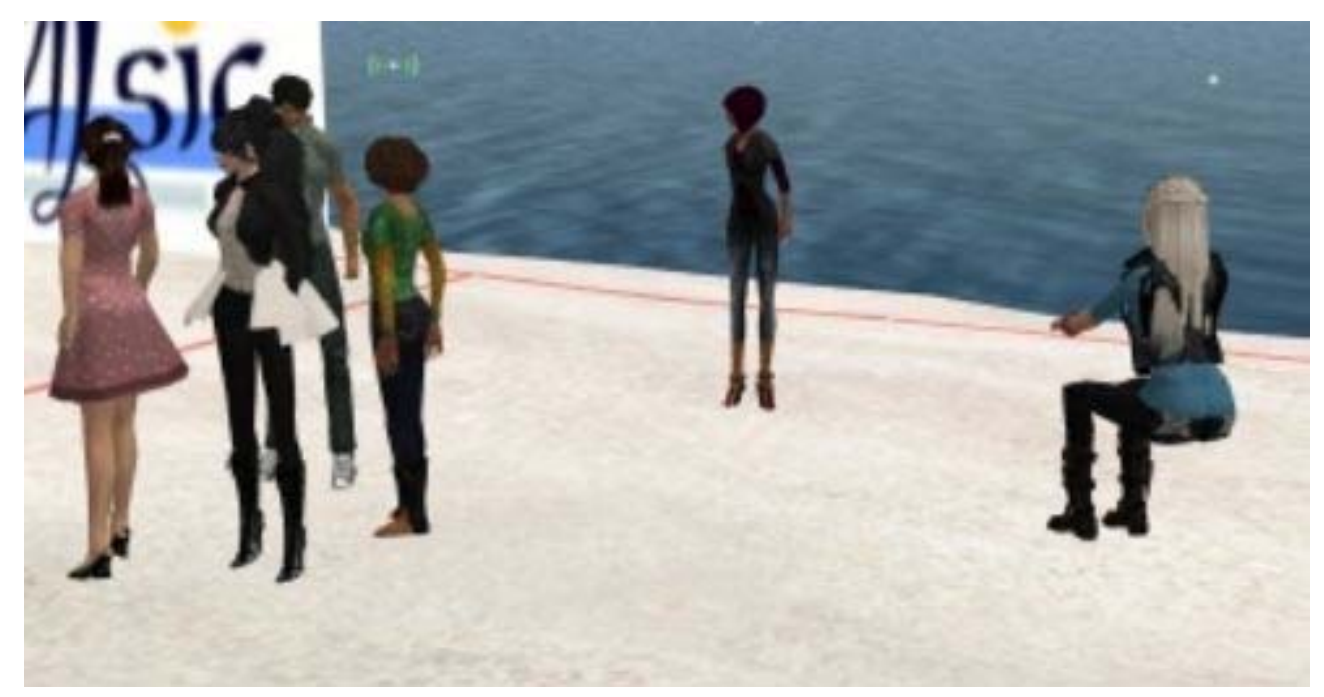

Fig. 10. Avatar proxemics 
Our data also shows that at the beginning of sessions, the language tutors (tfrez 2 in the example), on numerous occasions, explicitly ask the students to organise the proxemic positioning of their avatars using the verbal mode before beginning activities (see example 8). During this organisation, the language tutors systematically use the names of the students' avatars. We interpret this as a shift from a face-to-face strategy concerning forms of address to one which is more suited to the synthetic world. Indeed, in face-to-face communication it is uncommon to mention interlocutors' names in each utterance when they are in front of the speaker. Rather, gaze and orientation of the speaker may have the same function.

\section{(8)}

[tpa, tfrez2, 1:14-1:29] Please can you just come and stand in a circle around me so perhaps Hallorrann you can just yep + Hallorann can you turn around so you are facing me + great and Romeorez a little bit forward please

Ventrella (2011: p8-9) explains the impact that nonverbal communication may have on the communication and perceptions of communication in synthetic worlds should users not be aware of their virtual "faux pas". He quotes the example of a popular avatar that started to get a bad reputation as a snob due to her nonverbal communication. This, despite extra attempts to be sociable. The computer-generated nonverbal communication meant that the avatar's gaze was frequently directed at nothing in particular. Although the user was not aware of snubbing people, the nonverbal communication of her avatar meant that she gained a bad reputation with other users. The language tutors in our experimentation seemed sensitive to this. They used the verbal mode to organise the nonverbal mode, so as to facilitate verbal communication but also aware of class dynamics: they helped students become aware of their avatar behaviour and positioning with respect to others. 


\section{Conclusion}

This paper develops an original methodological framework for the study of multimodal communication in the synthetic world SL. In response to specific learning goals of an architectural CLIL course, the study applies this framework to examine how verbal and nonverbal modes were used during a collaborative building activity in students' L2 and how this usage differs from face-to-face contexts.

Our work proposes a classification of the communication possibilities in SL and offers a description of the verbal and nonverbal modes of communication. We have underlined relationships between the two modes that are built into the environment. For example, the link between users' proxemic acts and the public audio modality and the links between iconic gestures and verbal acts of interjection. We also highlighted some of the differences between SL's communication modes with respect to those of face-to-face communication, exemplifying how these may be of interest for communication within pedagogical contexts. For example, multidirectional synchronous written communication possibilities and the use of iconic gestures rather than facial expressions to display emotional states.

Our study of the collaborative building activity, based on a method to organise the data collected in screen recordings and its coding and transcription, suggests that the distribution of the use of the verbal and nonverbal modes is dependent on the role that the student undertook during the activity and the particular instructions that the student in each role was given: students in the helper role predominantly preferring verbal communication whilst students in the worker role preferred nonverbal communication. However, interaction between the two modes was apparent. The nonverbal modality of avatar movement was used as a strategy to overcome verbal miscommunication in particular concerning direction 
and orientation. Avatar movement also had the function of securing the context for verbal deictic references to objects. Such references were infrequently used in the verbal communication. Both helpers and workers preferred references to objects by object name, size and colour. We suggest that this is a sign that the students adapted to the environment: such references avoid ambiguity whilst deictic references are hard to understand due to participants being unaware as to whether they share visual access to the collaborative activity space or not. The camera feature of the environment, unavailable in the first world, contributes to this uncertainty. Should language tutors wish to exploit the synthetic world environment, thus, for "learning by building", it may be important to develop the proficiency of learners to express orientation and direction in the design of the pedagogical scenario. For example, by providing scaffolding activities.

Interaction between both modes was also evident concerning the proxemic organisation of students. Proxemic norms for communication from the first world were not immediately transferred inworld: students did not instinctively place their avatars in the formation of groups or facing each other. The data analysis further suggests that the proxemic organisation of students had an impact on the quantity of the students' verbal production and the topics discussed in this mode. Our study shows that proxemic closeness is important for $L 2$ activities which involve collaboration and, more specifically, building. There is, thus, a need in pedagogical scenarios to explicitly introduce students to the nonverbal communication in the environment to accelerate the emergence of communication norms when students work together. In doing so, we believe, language production and learning in subsequent collaborative activities can be facilitated.

Three-dimensional synthetic worlds introduce possibilities for nonverbal communication in distance language learning. We hope our paper will contribute to some of the 32 
methodological reflections needed to better understand the affordances of such

environments, including the possibilities they offer for nonverbal communication.

\section{References}

Antonijevic, S. (2008) From Text to Gesture Online; A microethnographic analysis of nonverbal communication in the Second Life virtual environment. Information, Communication and Society, 11(2): 221-238.

Brinton, D., Snow, M., \& Wesche, I. (2003) Content-based second language instruction. Michigan: The University of Michigan Press.

Chanier, T., Wigham, C.R. \& Saddour, I. (2011). (Eds.) Learning and Teaching Corpus (LETEC) of ARCHI21, Mulce.org [oai: mulce.org:mce-archi21-letec-all; http://repository.mulce.org ]

Ciekanski, M., \& Chanier, T. (2008) Developing online multimodal verbal communication to enhance the writing process in an audio-graphic conferencing environment. ReCALL, 20(2): 162-182.

Clark, H. H., \& Krych, M. A. (2004) Speaking while Monitoring Addressees for Understanding. Journal of Memory \& Language, 50(1): 62-81.

Coyle, D., Hood, P., \& Marsh, D. (2010). Content and Language Integrated Learning. Cambridge: Cambridge University Press.

Dalgarno, B., \& Lee, M. J. W. (2010) What are the Learning Affordances of 3-D virtual Environments? British Journal of Educational Technology, 41: 10-32.

Dalton- Puffer, C., Smit, U. (2007) (eds.) Empirical perspectives on CLIL classroom discourse. Frankfurt: Lang.

De Freitas, S. (2006) Learning in immersive worlds: a review of game-based learning. A report for the JISC e-Learning Programme. http://www.jisc.ac.uk/whatwedo/programmes/elearninginnovation/outcomes

Falloon, G. (2010) Using avatars and virtual environments in learning: What do they offer? British Journal of Educational Technology, 41(1): 108-122.

Fraser, M. (2000) Working with Objects in Collaborative Virtual Environments. Doctoral Thesis. University of Bristol. http://www.cs.bris.ac.uk/ fraser/phd

Gold, R. (1958). Roles in sociological field observation. Social Forces, 36: 217-213.

Gullberg, M. (Forthcoming -2012) Gestures in Second Language Acquisition (Cognitive Science and Second Language Acquisition). Routledge.

Henderson, M., Huang, H., Grant, S., \& Henderson, L. (2009) Language Acquisition in Second Life: improving self-efficacy beliefs. Proceedings ascilite. http://www.ascilite.org.au/conferences/auckland09/procs/henderson.pdf 
Jeffrey, P. \& Mark, G. (1998) Constructing Social Spaces in Virtual Environments: A study of Navigation and Interaction. In: Hook, K., Munro, A. \& D. Benyon (eds.) Workshop on Personalised and Social Navigation in Information Space, Stockholm: Swedish Institute of Computer Science, 24-38.

Kendon, A. (1982) The study of gesture: some observations on its history, Recherches Semiotique/Semiotic Inquiry, 2(1): 25-62.

Kraut, R. E., Fussell, S. R., \& Siegel, J. (2003) Visual information as a Conversational Resource in Collaborative Physical Tasks. Human Computer Interaction, 18(1): 13-49.

Lessikar,P . (2000) Business Communication: Theory and application. New Delhi: All India Traveller Books seller.

Lim, K. (2009) Pedagogy, Education and Innovation in 3-D Virtual Worlds. Journal of Virutal Worlds Research, 2(1): 3-11.

Marsh, D., Marsland, B. and Stenberg, K. (2001) Integrating Competencies for working life, Unicom: University of Juvaskyla.

McCafferty, S.G. \& Stam, G. (2008) Gesture: Second Language Acquisition and Classroom Research. New York: Routledge.

McNeill, D. (2000) (ed.) Language and Gesture. Cambridge: Cambridge University Press.

Mulce (2010) Site explaining the methodology used to compile LETEC Corpora. http://mulce.org

Nowak, K., \& Biocca, F. (2004) The effect of agency and anthropomorphism on users' sense of telepresence, copresence, and social presence in virtual environments. Presence: Teleoperators \& Virtual Environments, 12(5): 481-494.

Ornberg, T. (2003) Linguistic presence on the Internet: Communication, worldview and presence in online virtual environments. Unpublished master's thesis, University of Umea. http://admin.humlab.umu.se/files/pdf/therese_duppsats.pdf

Peachey, A., Gillen, J., Livingston, D., \& Smith-Robbins, S. (2010) Research Learning in Virtual Worlds. London: Springer.

Peterson, M. (2010) Learner participation patterns and strategy use in Second Life: an exploratory case study, ReCALL, 22(3): 273-292.

Saddour, I., Wigham, C.R. \& Chanier, T. (2011). Manuel de transcription de données multimodales dans Second Life. http://Irl-diffusion.univbpclermont.fr/mulce/metadata/FormationMulce/Formationmulcedocuments/archi21-conventions_transcript_SL_110901.pdf

Schwienhorst, K. (2002) The state of VR: A meta-analysis of virtual reality tools in second language acquisition. CALL, 15(3): 221-239.

Ventrella, J. (2011). Virtual Body Language. The History and Future of Avatars: How Nonverbal Expression is Evolving on the Internet. Eyebrain Books. 
Verhulsdonck, G. \& Morie, J.F. (2009). Virtual Chironomia: Developing Non-verbal Communication Standards in Virtual Worlds. Journal of Virtual Worlds Research, 2(3): 3-10.

Vetter, A. and Chanier, T. (2006) Supporting oral production for professional purpose, in synchronous communication with heterogeneous learners, ReCALL, 18 (1). pp.5-23.

Wadley, G. \& Gibbs, M. (2010). Speaking in character: Voice communication in virtual worlds, in William Sims Bainbridge (Ed.) Online worlds: Convergence of the real and the virtual. London: Springer.

Wigham, C.R. \& Chanier, T. (2011) Communication in Second Life. Research Laboratory Report. Clermont-Ferrand: LRL-Université Blaise Pascal.

Yee, N., Bailenson, J.N. Urbanek, M., Chang, F. \& Merget, D. (2004) The unbearable likeness of being digital: the persistence of nonverbal social norms in online virtual environments. Cyber Psychology and Behaviour, 10(1): 115-121. 